\title{
Mechanical Characteristics Testing of Biodegradable Ramie Fiber Reinforced Polylactic Acid (PLA) Fabricated with Hot-Press Molding
}

\author{
Roni Sujarwadi*, Tresna Priyana Soemardi \\ Mechanical Engineering Department, Faculty of Engineering, Universitas Indonesia, \\ Kampus Baru UI Depok, Jawa Barat 16424, Indonesia. Tel. +62-21-7270032, Fax. +62-21-7270033. \\ Email*: r.sujarwadi@gmail.com
}

\begin{abstract}
In this research, composite material was fabricated from both renewable resources and biodegradable materials: ramie woven fabric as reinforcement and 3D printed polylactic acid (PLA) filament as resin matrix. The laminate composites were produced using a film stacking method and processed using hot-press molding. The mechanical properties of woven ramie fabric, PLA matrix, and laminate composites were investigated. It is shown that the breaking force of the plain woven ramie fabric in the warp direction was greater than in the weft direction. Further, the tensile and impact properties of laminate at warp direction higher than weft direction when ramie fabric reinforcement is used. In addition, scanning electron microscopy examination of laminate composite showed good bonding between ramie fiber and PLA matrix. In summary, laminated composites based on polylactic acid and woven ramie fabric display good performance capability, which can use for the development of engineering applications.
\end{abstract}

Keywords: Biodegradable, mechanical characterization, PLA, ramie.

\section{INTRODUCTION}

Pollution caused by plastics has become one of the most pressing environmental problems, due to the large increase in the production of disposable plastic products as population growth. Countries in Asia and Africa have a very severe problem of plastic pollution, where the garbage collection system is still neglected. But the developed world, especially in countries with low recycling rates, still have problems regarding the collection of used plastic (Laura Parker 2019). For this reason, it is necessary to use biodegradable plastic materials to prevent or reduce pollution in the use of synthetic plastics. One of the biodegradable plastics that can be an alternative to synthetic plastics is polylactic acid (PLA). PLA is a biodegradable and biocompatible polymer that can be applied to various industries, especially in packaging and biomedical materials (Sengupta et al. 2018). By reinforcing PLA with some natural fibers, PLA is expected to replace synthetic plastic (Yusoff et al. 2016; Chin et al. 2017; Alias et al. 2018). The use of natural fibers as reinforcement is so that the composite material produced can be fully biodegradable so that it can be called biocomposite (Alias et al. 2018; Chaitanya et al. 2019; Komal et al. 2019).

Several studies have reported that PLA can be reinforced with several types of natural fibers, for example with kenaf (Yusoff et al. 2016; Alias et al. 2018, Hassan et al. 2018), ramie ( $\mathrm{Yu}$ and Li 2014; Yu et al. 2014; Yu et al. 2015), jute (Aguilar et al. 2018; Rajesh et al. 2018; Jiang et al. 2019), and bamboo (Sukmawan et al. 2016; Sinha et al. 2018; Li et al. 2019).
From these natural fibers, ramie is a natural fiber that has mechanical properties, especially tensile is quite good and easy to obtain because it can be cultivated in Indonesia. Furthermore, ramie fiber will be used as reinforced in PLA matrix in this study.

Recently, PLA is an expensive and hard to get material in Indonesia. PLA available in the Indonesian market is PLA which is commonly used for 3D printing. For this reason, this research will use PLA material for 3D printing, and will see how its mechanical properties when reinforced with ramie fabric. In this article, it is presented the preparation and mechanical characterization of an environmental friendly composite material manufactured from woven ramie fabric and polylactic acid (PLA). The evaluation of mechanical properties of ramie fabric, PLA matrix and laminate were determined. The specimens were prepared and tested according to the ASTM standard.

\section{MATERIALS AND METHODS}

\section{Study area}

The PLA polymer used in this research was transparent 3D printer PLA filament CCTREE A8012 with the diameter of $1.75 \mathrm{~mm}$ from 3D Zaiku Indonesia with raw material was imported from Natureworks.

The plain woven ramie fabrics were manufactured in Majalaya Textile Production Center, Bandung, West Java Indonesia using ramie fiber yarns from Koperasi Pondok Pesantren Darussalam, Garut, West Java, Indonesia. 


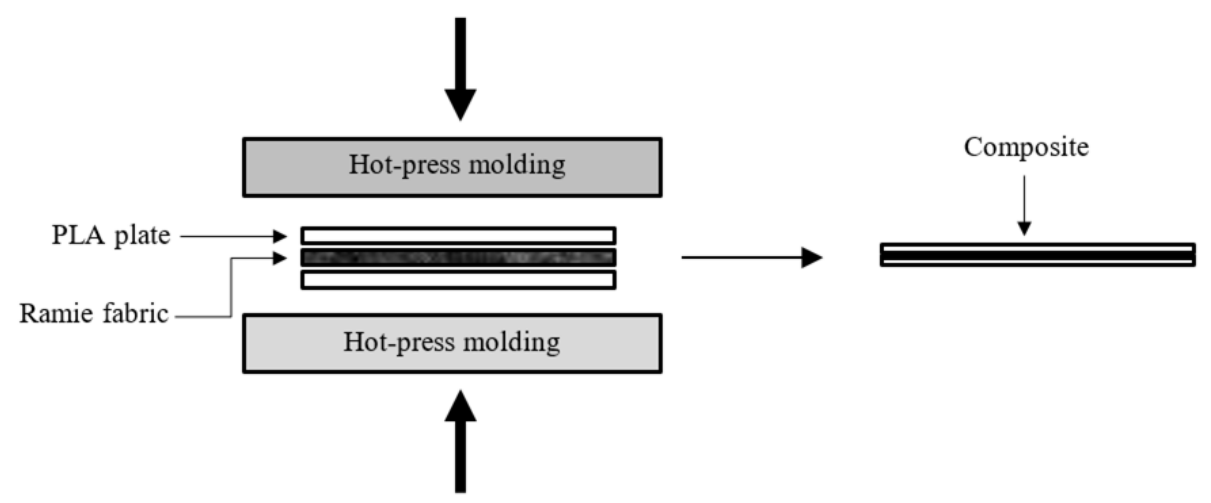

Figure 1. Schematic of process for fabricating PLA/Ramie fabric composites.

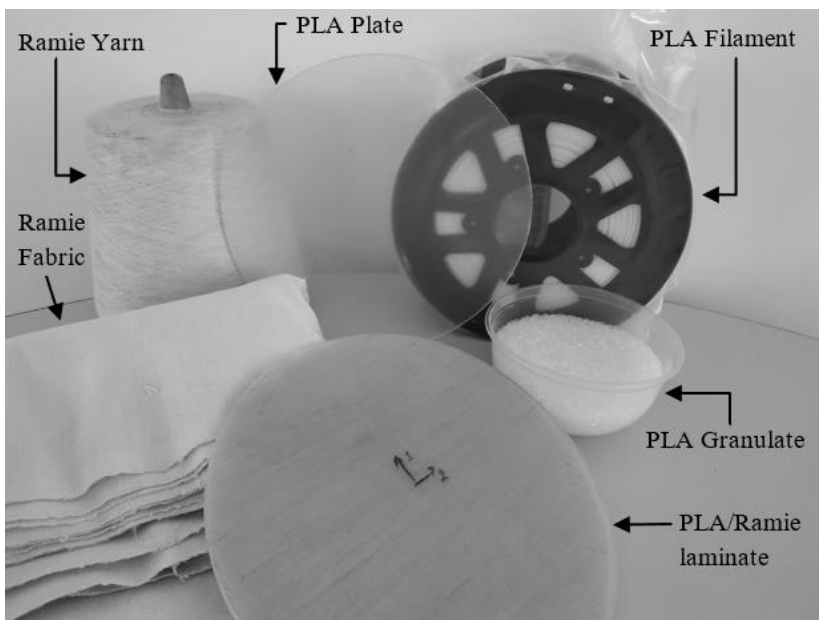

Figure 2. Materials and PLA/Ramie fabric laminate taken by author in Laboratory.

\section{Procedures}

\section{- Composite preparation}

The PLA filament was cut into PLA granulate using strand pelletizer CSG 171/1 Collin GmbH. The PLA plate was produced using hot-press molding with the mold temperature of $200^{\circ} \mathrm{C}$ and the pressure of $0.5 \mathrm{MPa}$.

Composite panels (17\% fiber volume fraction) were produced using a film-stacking procedure, the layers of ramie fabrics and PLA plate were piled up alternately as shown schematically in Figure 1. Layers of PLA plate and ramie fabric were compression molded with a conventional hot-press molding Toyoseiki Mini Test Press-10. The process condition for making composite panel was the same as process condition for making PLA plate. Figure 2 shows the materials and PLA/Ramie fabric laminate.

\section{- Tensile test}

Fabrics. Ramie fabrics were tensile tested according to ASTM D 5035-11 on a Shimadzu Universal Tensile Tester, model AGS-10kNG. Fabric specimens prepared by the raveled strip method with the dimension of 50 $\mathrm{mm} \times 150 \mathrm{~mm}$. The fabrics were characterized in both warp and weft directions. Tensile tests were performed at a crosshead speed of $300 \mathrm{~mm} /$ minutes and a gauge length of $75 \mathrm{~mm}$. Five specimens were tested to obtain average tensile properties.

Polylactic acid (PLA). Tensile testing was carried out on a Shimadzu Universal Tensile Tester, model AGS$10 \mathrm{kNG}$ according to the ASTM D 638-14, with type IV specimen. Five specimens were tested with a crosshead speed of $5 \mathrm{~mm} / \mathrm{min}$ and gauge length of $50 \mathrm{~mm}$ to obtain average tensile properties.

Composite. Tensile properties of PLA/Ramie fabric laminates were characterized in accordance with ASTM D 3039/D 3039M-17. Tensile test was carried out using a Shimadzu Universal Tensile Tester, model AGS$10 \mathrm{kNG}$. The machine was operated at a crosshead speed of $5 \mathrm{~mm} / \mathrm{min}$. Five specimens were tested to obtain average tensile properties composite.

\section{- Flexural test}

Flexural test was conducted as per ASTM D 790-17. Specimens were loaded in three point bending with a recommended span to depth ratio of 16:1. The test was conducted on the same machine tensile test. Five specimens were tested and average result was obtained.

\section{- Impact test}

The impact resistance of PLA/Ramie fabric composite in comparison to a pure PLA material was determined on unnotched izod test specimens in accordance with ASTM D 256-10 using CEAST Resil Impactor Junior. The tests were performed with energy pendulum of 2 Joule. A total of 5 samples of PLA and 5 of PLA/Ramie fabric composite were tested to determine mean impact resistance.

\section{- Scanning electron microscope}

The specimens were coated with a thin layer of platinum $(\mathrm{Pt})$ to get good conductivity, using Jeol Auto Fine Coater, model JFC-1600 apparatus before examination. The Ramie fiber and the fracture surfaces of tensile tests PLA/Ramie fabric specimens were observed by Jeol Analytical Scanning Electron Microscope (SEM), model JSM-6510LA. 


\section{RESULTS AND DISCUSSION}

\section{Tensile test}

Ramie fabric tensile properties such as breaking force and percent apparent of elongation in both axial $\left(0^{\circ}\right.$-warp direction) and transverse $\left(90^{\circ}\right.$-weft direction) directions are summarized (Table 1). It was found that the breaking force in the axial and the transverse directions are different (Figure 3). Fracture type of ramie fabric at axial direction and test condition was shown (Figure 4). The plain woven ramie fabric has higher breaking force in the axial direction, as compared to the transverse direction. This occurs because the number of fibers at the same distance in the axial direction is more than the transverse direction. The tensile strength of rami fabric mostly 400-1000 MPa. In this case tensile strength of rami fabric 16.77 $\mathrm{MPa}$ at transverse direction and 22.94 $\mathrm{MPa}$ at axial direction. The duration and storage condition of sample might be causing it.

According to tensile test result of PLA and laminate composite, PLA has higher tensile strength compare to laminate at axial direction and transverse direction (Figure 5). Effect of reinforcement in laminate composite is not enough to improve PLA because tensile of ramie fabric lower than PLA as shown (Table 2). All specimens showed same type of fracture, brittle fracture as shown (Figure 6).
Table 1. Tensile properties of ramie fabric.

\begin{tabular}{llll}
\hline $\begin{array}{l}\text { Test } \\
\text { direction }\end{array}$ & $\begin{array}{l}\text { Maximum } \\
\text { force (N) }\end{array}$ & $\begin{array}{l}\text { Tensile } \\
\text { strength } \\
\text { (MPa) }\end{array}$ & $\begin{array}{l}\text { Elongation } \\
\text { at break (\%) }\end{array}$ \\
\hline $\begin{array}{l}\text { Axial }\left(0^{\circ}-\right. \\
\text { warp }\end{array}$ & 745.50 & $22.94(2.03)$ & $28.62(5.14)$ \\
direction) & $(66.08)$ & & \\
\hline $\begin{array}{l}\text { Transverse } \\
\left(90^{\circ} \text {-weft }\right.\end{array}$ & 545.00 & $16.77(1.88)$ & $11.71(3.76)$ \\
direction) & $(61.06)$ & & \\
\hline Note: Values in parentheses are standard deviations. &
\end{tabular}

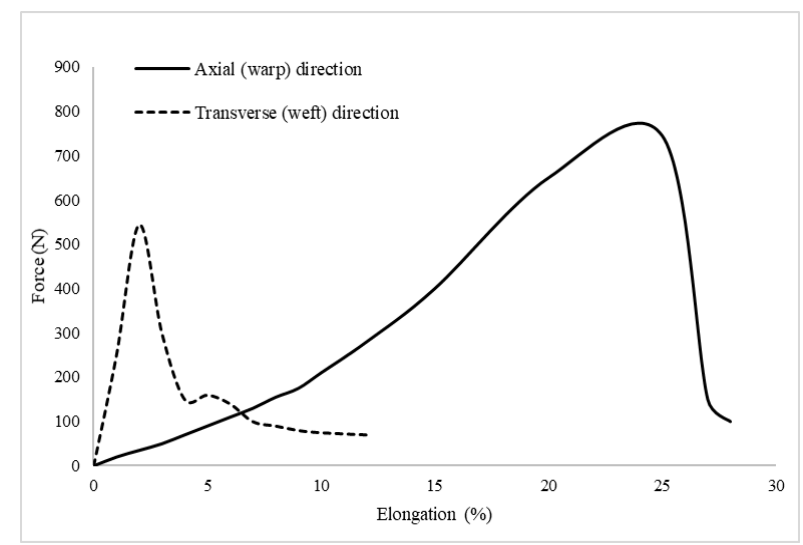

Figure 3. Typical Force-elongation diagram for ramie fabric in both axial, and transverse direction.

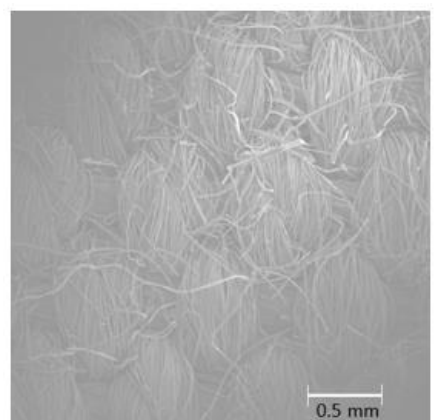

(a)

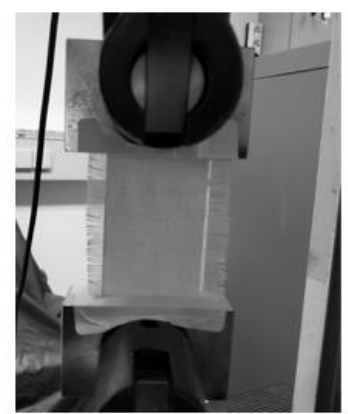

(b)

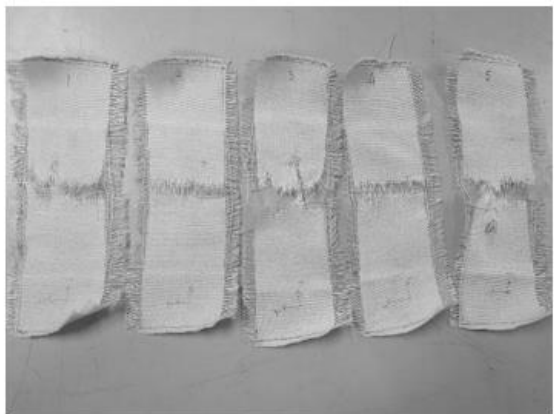

(c)

Figure 4. (a) Ramie fabric, (b) Tensile test for ramie fabric, (c) Tensile fracture specimen

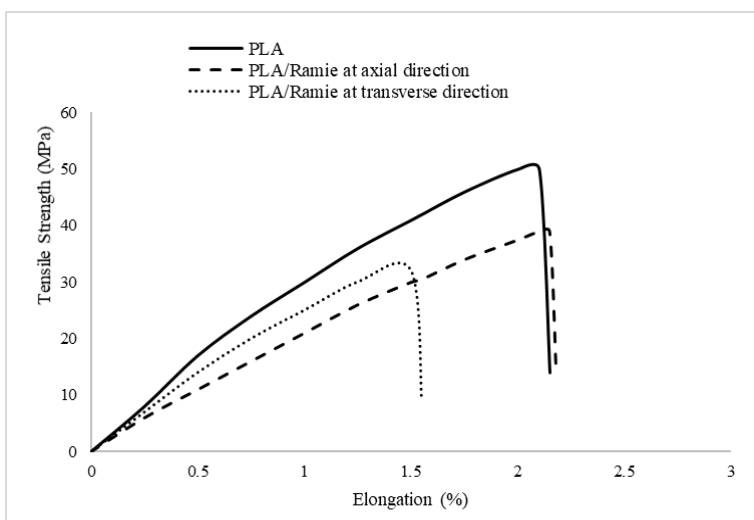

Figure 5. Typical tensile stress-elongation diagram for PLA and PLA/ramie fabric laminate.

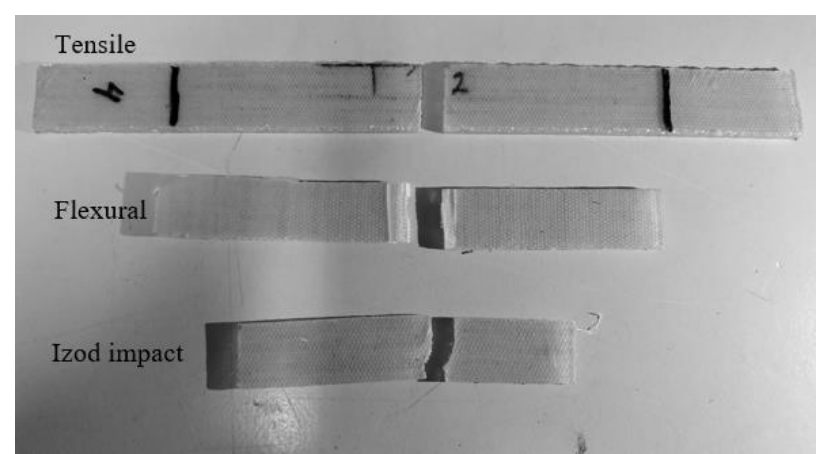

Figure 6. Tensile, flexural, and izod impact resistance fractured laminate. 


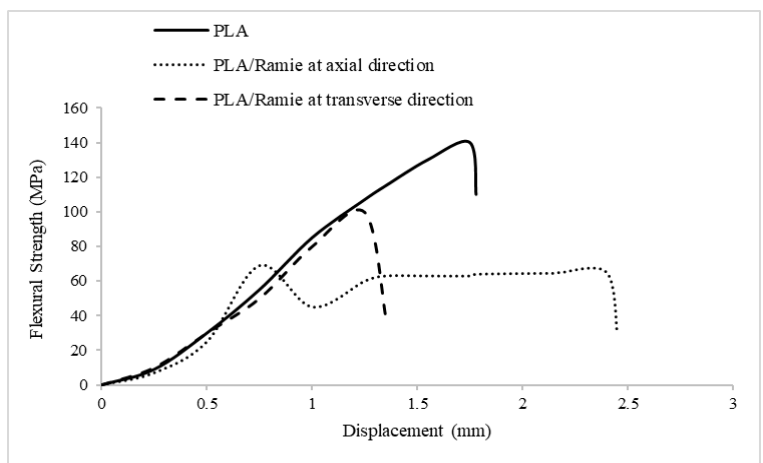

Figure 7. Typical flexural stress-displacement diagram for PLA and PLA/ramie fabric laminate.

\section{Flexural test}

The results of flexural tests are shown in (Table 2). The average flexural strength of composite in both directions axial and transverse are $68.77 \mathrm{MPa}$ and $91.11 \mathrm{MPa}$, respectively. An exception occurs where axial direction has a lower strength than transverse direction. It might be come from the preparation of specimens. PLA has a greater flexural modulus and flexural strength. Deterioration in flexural strength about $53 \%$ at axial direction and $37 \%$ at transverse direction to PLA occurred when ramie fabric is used to reinforce PLA. It caused by the low quality of ramie fiber as reinforcement like at tensile so it has a direct effect on the laminate composite. Composite laminate at axial direction has the longest displacement before break compare to PLA and laminate at transverse direction (Figure 7). During the test no specimen has failed by delamination and the failure mode shows no fiber pull-out.

Table 2. Mechanical properties of PLA, commercial synthetic resins and PLA/Ramie fabric laminate.

\begin{tabular}{llllll}
\hline Mechanical properties & $\begin{array}{l}\text { PLA/Ramie fabric at } \\
\text { axial direction }\end{array}$ & $\begin{array}{l}\text { PLA/Ramie fabric at } \\
\text { transverse direction }\end{array}$ & PLA & Epoxy & Polyester \\
\hline Tensile strength (MPa) & $39.19(1.55)$ & $31.79(1.30)$ & $49.50(5.34)$ & $35-100$ & $40-90$ \\
Tensile elongation (\%) & $2.32(0.27)$ & $1.38(0.10)$ & $2.03(0.41)$ & $1.0-6.0$ & $2.0-5.0$ \\
Tensile modulus (GPa) & $2.51(0.10)$ & $3.07(0.14)$ & $3.34(0.13)$ & $3.0-6.0$ & $2.0-4.5$ \\
Flexural strength (MPa) & $68.77(11.43)$ & $91.11(7.64)$ & $146.50(11.69)$ & - & - \\
Flexural modulus (GPa) & $3.22(0.54)$ & $3.67(0.86)$ & $4.38(1.04)$ & - & - \\
Impact resistance $\left(\mathrm{kJ} / \mathrm{m}^{2}\right)$ & $14.96(2.13)$ & $10.99(2.52)$ & $17.49(3.25)$ & - & - \\
\hline
\end{tabular}

Note: Values in parentheses are standard deviations.

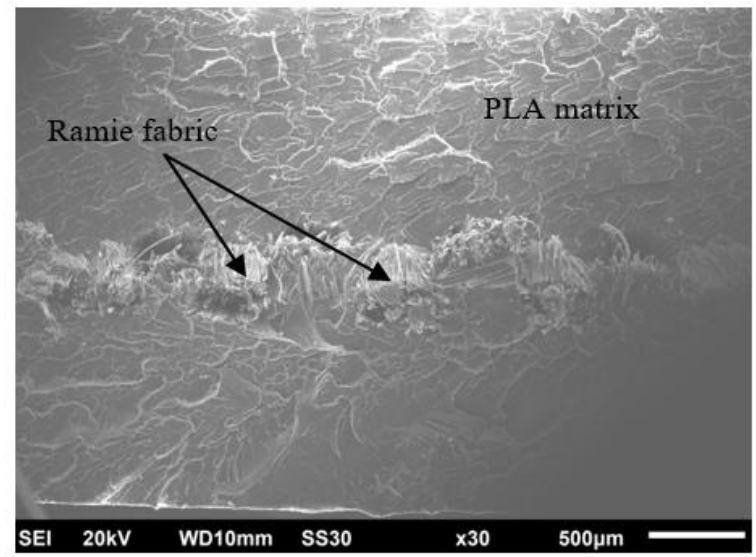

(a)

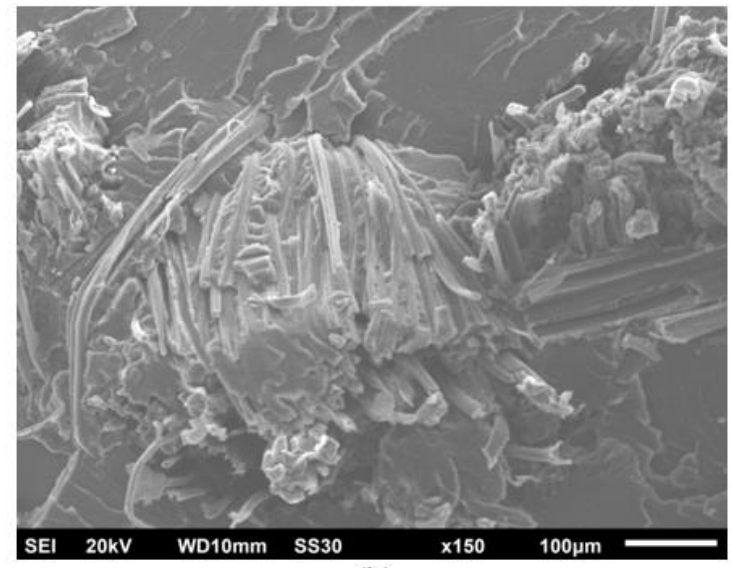

(b)

Figure 8. The SEM photograph of the PLA/Ramie fabric laminate tensile fracture, (a) Structure of laminate, (b) Matrix cracking.

\section{Impact resistance test}

The results of unnotched Izod impact tests are shown in (Table 2). The average impact energy unit area of composite in both directions axial and transverse are $14.96 \mathrm{~kJ} / \mathrm{m}^{2}$ and $10.99 \mathrm{~kJ} / \mathrm{m}^{2}$, respectively. The two previous tests shown that PLA has the best performance compared to laminated composites because of the poor quality of ramie fabric. All specimen presented a complete break where the specimen separates into two pieces (Figure 6). In addition, the kinetic energy of the pendulum was transferred to the laminate during the contact, and consumed in the generation of damage. In terms of mechanical properties, the composite laminate still presented excellent energy absorption capabilities for engineering applications. 


\section{Scanning electron microscope}

Scanning electron microscope photographs of fractured surface of the composite after tensile test are shown in (Figure 8). As can be seen from (Figure 8-a), the composite was fabricated with one layer and it is possible to see different fabric and resin layer. At high magnification, the SEM photomicrograph of (Figure 8-b) show a matrix cracking at axial direction to the tensile loading and staggered brittle failure. It can also be seen in (Figure 9-a) the yarns in warp and weft directions, their fracture at different length and few cavities left by the pulled-out fibers.

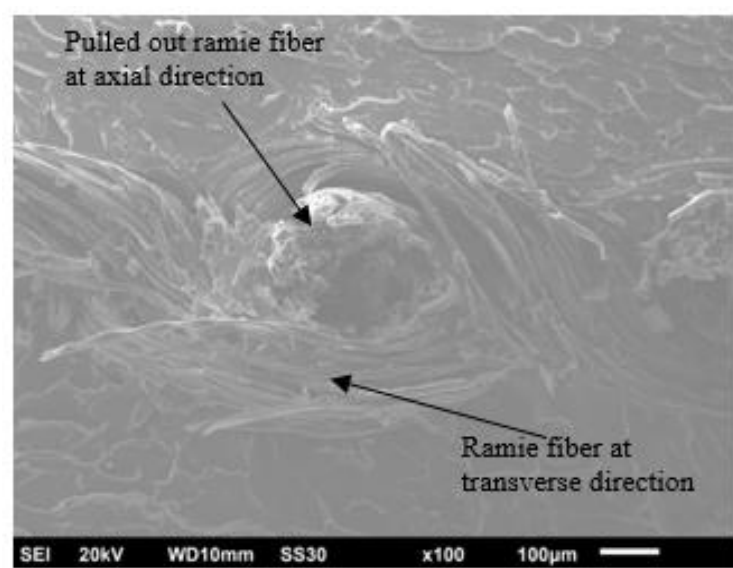

(a)

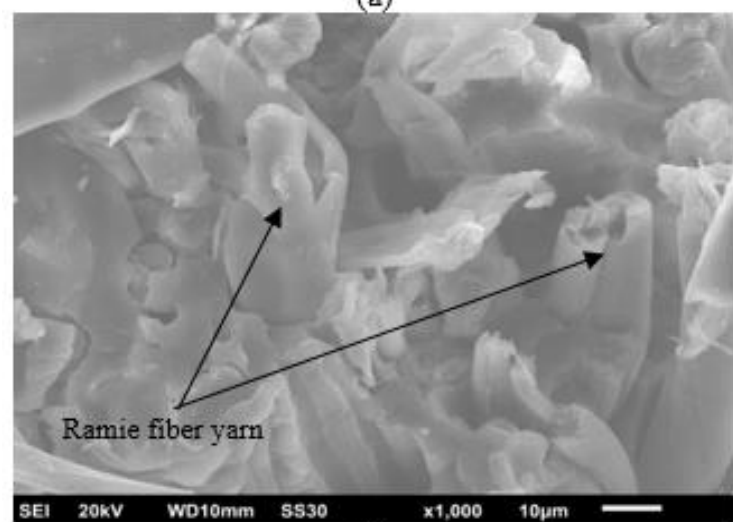

(c)

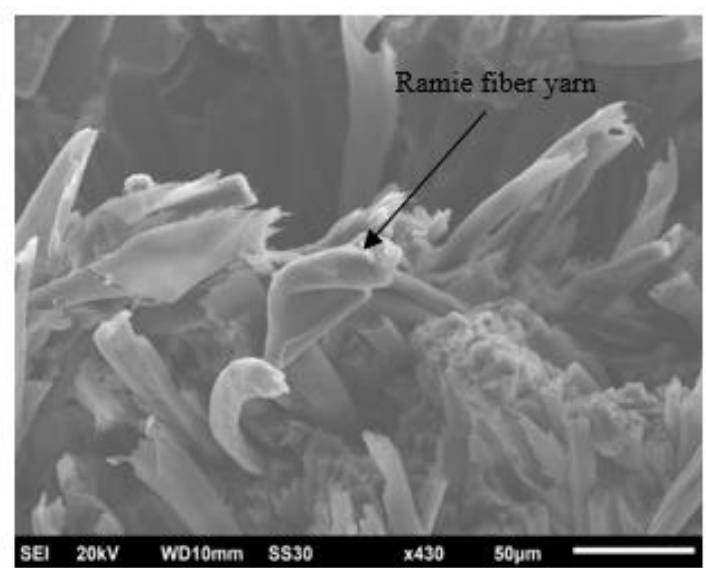

(b)

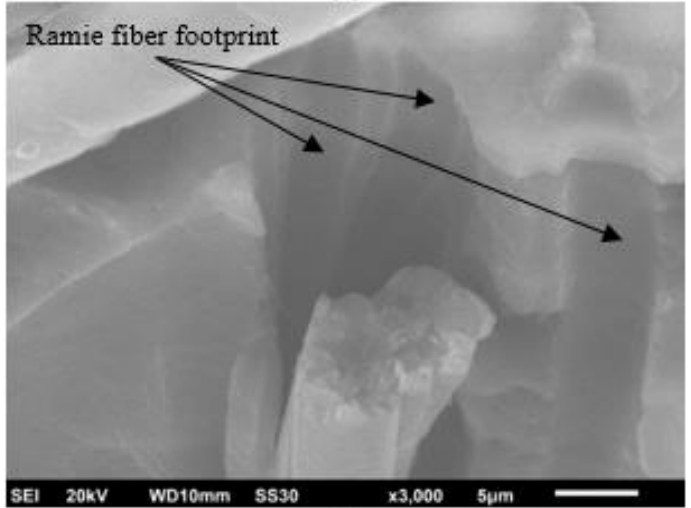

(d)

Figure 9. The SEM image showing a well bonded ramie fiber in the PLA matrix, (a) Fracture of yarn at different length, (b) Ramie fiber yarn, (c) Fiber bundles are attached to each other by the matrix, (d) Adhesion between the ramie fibers and the PLA matrix.

Furthermore, (Figure 9-b) shows SEM micrographs of single fibers. In contrast, (Figure 9-c) show that the fiber bundles are attached to each other by the matrix, which indicates that the PLA penetrates the yarn. Additionally, Figure 9(d) exhibit that ramie fibers are well bonded to PLA matrix, gaps in the fiber and polymer interface are not found and the PLA matrix and the fiber surfaces are not clean, which indicates good adhesion between the ramie fibers and the PLA matrix.

\section{Discussion}

In this work, Ramie fabric and 3D printed PLA filament were used to fabricate fully biodegradable laminate, an attractive combination of mechanical properties with their environmental friendly character. According to tensile test of fabric, the warp direction has higher breaking force compared to the weft direction. In reference to the characterization of the laminate composite, laminate with warp direction higher than weft direction. Also scanning electron microscopy analysis showed good bonding between Ramie fiber and PLA matrix.

\section{ACKNOWLEDGEMENTS}

We would to thank Center for Polymer Technology (BTP) from Agency for Assessment and Application of Technology (BPPT) for laboratory support in this research.

\section{REFERENCES}

Aguilar MD, Ortega HO, Mendez JA, Camps J, Espinach FX, Mutje P. 2018. The role of lignin on the mechanical 
performance of polylactic acid and jute composites. International Journal of Biological Macromolecules 116: 299304.

Alias NF, Ismail H, Ishak KMK. 2019. The Effect of Kenaf Loading on Water Absorption and Impact Properties of Polylactic Acid/ Natural Rubber/ Kenaf Core Powder Biocomposite. Proceeding of International Conference on Recent Advances in Materials, Minerals \& Environment (RAMM) 2018. Penang, Malaysia, 27-29 November 2018.

Chin DDVS, Yahya MNB, Din NBC, Ong P. 2018. Acoustic properties of biodegradable composite micro-perforated panel (BC-MPP) made from kenaf fibre and polylactic acid (PLA). Applied Acoustics 138: 179-187.

Chaitanya S, Singh I, Song JI. 2019. Recyclability analysis of PLA/Sisal fiber biocomposites. Composite Part B: Engineering 173: 106895.

Hassan NAA, Ahmad S, Chen RS, Zailan FD, Shahdan D. 2019. Effect of processing temperature and foaming agent loading on properties of polylactic acid/kenaf fiber composite foam. Proceeding of Nanotech Malaysia 2018. Kuala Lumpur, Malaysia, 7-9 May 2018.

Jiang N, Yu T, Li Y, Pirzada TJ, Marrow TJ. 2019. Hygrothermal aging and structural damage of a jute/poly (lactic acid) (PLA) composite observed by X-ray tomography. Composites Science and Technology 173: 15-23.

Komal UK, Lila MK, Singh I. 2019. PLA/banana fiber based sustainable biocomposites: A manufacturing perspective. Composite Part B: Engineering 180: 107535.

Laura Parker. 2019. The world's plastic pollution crisis explained. Published 7 June 2019. www.nationalgeographic.com

Li W, He X, Zuo Y, Wang S, Wu Y. 2019. Study on the compatible interface of bamboo fiber/polylactic acid composites by in-situ solid phase grafting. International Journal of Biological Macromolecules 141: 325-332.
Rajesh G, Prasad AVR, Gupta AVSSKS. 2018. Water Absorption Characteristics of Successive Alkali Treated Jute/Polylactic Acid Composites. Proceeding of International Conference on Advances in Materials and Manufacturing Applications (IConAMMA-2017). Bangaluru, India, 17-19 August 2017.

Sengupta S, Manna S, Roy U, Das P. 2018. Manufacturing of Biodegradable Poly Lactic Acid (PLA): Green Alternatives to Petroleum Derived Plastics. Elsevier Inc.

Sinha R, Purohit R, Mishra V. 2018. Density Variation due to Polylactic Acid of Long Bamboo Fibres. Proceeding of Materials Processing and characterization. Hyderabad, India, 16-18 March 2018

Sukmawan R, Takagi H, Nakagaito AN. 2016. Strength evaluation of cross-ply green composite laminates reinforced by bamboo fiber. Composite Part B: Engineering 84: 9-16.

$\mathrm{Yu} \mathrm{T}, \mathrm{Li}$ Y. 2014. Influence of poly (butylenes adipate-coterephthalate) on the properties of the biodegradable composites based on ramie/poly (lactic acid). Composites Part A: Applied Science and Manufacturing 58: 24-29.

Yu T, Jiang N, Li Y. 2014. Study on short ramie fiber/poly (lactic acid) composites compatibilized by maleic anhydride. Composites Part A: Applied Science and Manufacturing 64: 139-146.

Yu T, Jiang N, Li Y. 2014. Functionalized multi-walled carbon nanotube for improving the flame retardancy of ramie/poly (lactic acid) composite. Composites Science and Technology 104: 26-33.

Yu T, Hu C, Chen X, Li Y. 2015. Effect of diisocyanates as compatibilizer on the properties of ramie/poly (lactic acid) (PLA) composites. Composites Part A: Applied Science and Manufacturing 76: 20-27.

Yusoff RB, Takagi H, Nakagaito AN. 2016. Tensile and flexural properties of polylactic acid-based hybrid green composites reinforced by kenaf, bamboo and coir fibers. Industrial Crops and Products 94: 562-573. 